\section{Innovational duality and sustainable development: finding optima amidst socio-ecological policy trade-off in post-COVID-19 era}

Innovational duality and sustainable development

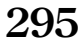

\author{
Avik Sinha
}

Centre for Excellence in Sustainable Development, Goa Institute of Management, Sanquelim, India

Arnab Adhikari

Operations Management, Indian Institute of Management Ranchi, Ranchi, India, and Ashish Kumar Jha Trinity Business School, Trinity College Dublin, Dublin, Ireland

\begin{abstract}
Purpose - This study aims to analyze the socio-ecological policy trade-off caused by technological innovations in the post-COVID-19 era. The study outcomes are utilized to design a comprehensive policy framework for attaining sustainable development goals (SDGs).

Design/methodology/approach - Study is done for 100 countries over 1991-2019. Second-generation estimation method is used. Innovation is measured by total factor productivity, environmental quality is measured by carbon dioxide $\left(\mathrm{CO}_{2}\right)$ emissions and social dimension is captured by unemployment.

Findings - Innovation- $\mathrm{CO}_{2}$ emissions association is found to be inverted $U$-shaped and innovationunemployment association is found to be $U$-shaped.

Research limitations/implications - The study outcomes show the conflicting impact of technological innovation leading to policy trade-off. This dual impact of innovation is considered during policy recommendation.

Practical implications - The policy framework recommended in the study shows a way to address the objectives of SDG 8, 9 and 13 during post-COVID-19 period.

Social implications - Policy recommendations in the study show a way to internalize the negative social externality exerted by innovation.

Originality/value - This study contributes to the literature by considering the policy trade-off caused by innovation and recommending an SDG-oriented policy framework for the post-COVID-19 era.
\end{abstract}

Keywords Innovation, SDG, COVID, $\mathrm{CO}_{2}$ emissions, Unemployment

Paper type Research paper

\section{Introduction}

Technological innovations, specifically digital innovations, are expected to generate higher amount of value and resources for the economy in the coming years (Unalan and Ozcan, 2020; Jha and Bose, 2015). Recent global disruptions like COVID-19 have exacerbated the need and the push toward higher levels of digitalization as well (Gurbuz and Ozkan, 2020). The role of

(c) Avik Sinha, Arnab Adhikari and Ashish Kumar Jha. Published by Emerald Publishing Limited. This article is published under the Creative Commons Attribution (CC BY 4.0) licence. Anyone may reproduce, distribute, translate and create derivative works of this article (for both commercial and noncommercial purposes), subject to full attribution to the original publication and authors. The full terms of this licence may be seen at http://creativecommons.org/licences/by/4.0/legalcode
Received 29 June 2021 Revised 14 September 2021 16 November 2021 Accepted 4 December 2021 
JEIM

35,1

296

such innovations in leading the world toward a more prosperous future cannot be understated. However, technological innovations have not always yielded equitable outcomes for all sections of the society (Van der Waal et al., 2021). Further, the ongoing COVID-19 pandemic has increased the inequalities that were initiated due to unequal distribution of benefits between different sections of society. This underlines the importance of policies that can bring about a more sustainable and equitable development.

The United Nations 2030 agenda for sustainable development comprising 17 sustainable development goals (SDGs) is one of the indicators that nations across the world have adopted to achieve sustainable development. The ongoing COVID-19 pandemic poses a serious question mark on attaining the SDGs by 2030. Mukarram (2020) has identified the dire impact of COVID-19 pandemic on nations' ability to meet their SDGs. In this backdrop, technological innovation can emerge as an important factor to meet SDGs in the post-COVID world. For instance, the change in work style, i.e. from the conventional office set up to remote working, highlights the importance of automation and digitization. It highlights the crucial role of technological innovations in attaining SDGs related to the livelihood of people. Hence, it can be concluded that technological innovation can be an instrumental factor in achieving SDGs in the post-COVID world. Recently, scholars have argued for increased usage of digital media to raise awareness for SDGs (Grover et al., 2021), usage of technological innovations to hasten meeting sustainability goals (Girbuz and Ozkan, 2020). Gupta et al. (2021) in a recent call for papers for this special issue highlighted the need for technological innovations to achieve SDGs in the post-pandemic world. In this study, we look at the role and the limiting effects of technological innovations in meeting SDGs.

While the above discourse points to the utility of technological innovation in enabling societies to meet their SDGs, technological innovations also have a dark side, especially with regard to social indicators such as employment. In this context, there exist two contradictory opinions. Scholars such as Greenan and Guellec (2000), Benavente and Lauterbach (2008) and so on opine that technological innovation can create new jobs. On the contrary, researchers such as Vivarelli (2015), Gagliardi (2019) and so on deduce that innovation often replaces manual labor with technology, thus raising unemployment. For instance, decline of coal mining leads to lower carbon footprint. This is on account of technological innovation due to higher reliance on hydrogen or solar energy as well as new mechanized mining technologies. However, it also leads to higher unemployment in the manual labor-intensive industry. As the example shows, technological innovations may lead to more sustainable development, but it is not always conducive to generating employment.

Now, achieving sustainability entails the accomplishment of economic, environmental and social dimensions of sustainability. Hence, the policy frameworks should maintain a balance between these three aspects. Whether an innovation is going to emerge as an environmental panacea or it is going to open pandora's box of social imbalances - emerges as a major question in the post-COVID world. In summary, attaining the objectives of Agenda 2030 is largely dependent on the innovation capacities of nations, while these innovations might deter the developmental trajectory by pushing the nations toward a social imbalance. To manage this probable problem, looking beyond the obvious benefits of innovation becomes necessary.

The impact and implications of the COVID-19 pandemic is still raging around us, and the implication of new policies have not yet been fully observed. In this study, we take a historical account of innovation strategies and their implications in terms of employment and meeting SDGs and attempt to create a policy framework for future. This study focuses on the following research question:

$R Q$. Will there be conflicting social and ecological impacts of technological innovation in attaining SDG objectives during the post-COVID-19 period? 
We hypothesize that in view of the innovation-led socio-ecological policy trade-off expected in the post-COVID-19 period, a policy reorientation is necessary. This policy reorientation might enable the nations to transform the prevailing economic growth trajectory and policy regimes toward the achievement of SDG objectives. In this pursuit, the present study empirically assesses the dual impact of innovation on $\mathrm{CO}_{2}$ emissions and unemployment for 100 countries over 1991-2019. The analysis is conducted across several income levels, for a broader impact assessment. Based on the outcomes, an SDG-oriented pro-developmental comprehensive policy framework has been recommended. This policy framework is designed in a way to internalize the negative social externalities of innovation, while enhancing its positive environmental externalities. This multipronged policy-driven approach to take account of the innovation-led policy trade-off has not been attempted in the academic literature, and there lies the policy-level contribution of the study. The need for such studies has also been highlighted by Hörisch (2021) who call for policy research to enable meeting SDGs in the post-COVID-19 world.

Now, to achieve this objective, a theoretical framework is required to capture the evolutionary impacts of the policy instruments. The framework should capture this impact across a group of countries. Moreover, the framework needs to take account of the associative nonlinearity among the model parameters. Hence, the environmental Kuznets curve (EKC) hypothesis has been adopted for the empirical analysis. Lastly, as the countries are associated with each other via economic spillovers, the estimation method needs to consider the crosssectional dependence (CD). Based on this assumption, second generation panel data estimation methods are used. This theoretical and methodological complementarity with the research objective sanction the analytical contribution of the study.

\section{Literature review}

The scholarly works related to this study can be classified into three works; scholarly works on impact of technological innovation on SDGs and $\mathrm{CO}_{2}$ emissions, impact of technological innovation on employment and impact of COVID-19 pandemic on SDG.

\subsection{Impact of technological innovation on sustainable development goals and carbon dioxide emissions}

In recent times, there is a rising interest among scholars to explore the effect of technological innovation on SDGs. Table 1 contains a summary of some of the major studies in the domain. While Mensah et al. (2018) explain how the technological development of the Organization for Economic Co-Operation and Development (OECD) countries influences their $\mathrm{CO}_{2}$ emissions over 1990-2014, Modgil et al. (2020) propose a modern information decision support system for achieving the SDGs. Sinha et al. (2020) investigate the effect of technological innovations on environmental degradation, sustained economic growth, clean and affordable energy, and quality of education for the period 1990-2017. Bag et al. (2021) opine that big data analyticsbased artificial intelligence can be an important factor for the operations of circular economy and achieving the SDGs. Chien et al. (2021) propose an information and communication technology (ICT)-based framework for the BRICS countries (Brazil, Russia, India, China, and South Africa) to combat environmental degradation and achieve the SDGs.

The exploration of the existing literature related to SDGs highlight the researchers focus on diverse topics such as performance indicators of food loss reduction (Al-Dalaeen et al., 2021), the influence of political leadership on the SDGs (Grover et al., 2021), information decision system-based framework design (Modgil et al., 2020), the impact of technological innovation on achieving SDGs (Sinha et al., 2020), humanitarian decision-making (Marić et al., 2021), etc. However, the investigation into the effect of technological innovation attaining the
Innovational duality and sustainable development 


\section{JEIM 35,1}

\section{8}

Table 1.

Summarized literature review

\begin{tabular}{ll}
\hline Scholarly works & Context \\
\hline $\begin{array}{l}\text { Mensah } \text { et al. } \\
(2018)\end{array}$ & OECD countries \\
Sinha et al. (2020) & Next 11 countries
\end{tabular}

China

(2021a)

Evangelista and Italy

Savona (2002)

Benavente and Chile

Lauterbach

(2008)

Evangelista and Nine countries of the European

Vezzani (2012)

Gagliardi (2019)

This work
UK

100 countries segregated into four different income categories (i.e. low, lower-middle, upper-middle and high)

SDGs and on the social indicator such as unemployment has not been paid enough attention. This is the gap our study aims to fill.

\subsection{Impact of technological innovation on employment}

Many researchers investigate the impact of technological progress on the employment of the economy. As per the analysis, there exist two contradictory opinions. A group of researchers opines that technological innovation raises the employment level of a nation. For instance, Greenan and Guellec (2000) investigate the impact of technological innovation on the employment opportunities for the French firms over 1986-1990 and find the strong positive effect of innovation at the firm level as well as sectoral level. Similarly, Benavente and Lauterbach (2008) conclude that the technological innovation policy of Chile generated new jobs over 1998-2011. Another stream of research that has recently been of much interest to scholars studying industrial revolution and employment implications is "Industry 4.0" (Koh et al., 2019; Xu et al., 2018). Industry 4.0 is also expected to significantly enhance firm productivity and employment in coming years (Ortt et al., 2020; Opazo-Basáez et al., 2021).

Another group of researchers believes that technological progress affects employment opportunities. Evangelista and Savona (2002) conduct an empirical study on the Italian firms over 1993-1995 and exhibit the negative effect of innovation on employment. Similarly, Gagliardi (2019) investigates the effect of foreign technological innovation on domestic employment through the industry mix of the UK over 2000-2007 and finds the reduction in employment by around 5\%. Recently, Zhu et al. (2021) present a dual effect of technological innovation in case of Chinese firms, i.e. process and product innovation shows the positive and negative impact, respectively, on employment opportunities. These studies indicate the need to be cognizant of technological innovations' impact. Higher unemployment might lead to social unrest, even though it is driven by noble goals of more sustainable development. 
The impact of the ongoing COVID-19 pandemic on attaining SDGs has attracted the attention of researchers. There is a rising interest in analyzing how innovations can help nations and firms meet their SDGs. Thornton (2020) opines that the pandemic has a severe negative impact on attaining the SDGs. Pan and Zhang (2020) highlight the importance of in-depth investigation into the information systems to attain the SDGs in the post-COVID era. Modgil et al. (2021) identify the role of AI in meeting firms' resilience in post-COVID-19 world.

However, our literature review finds lack of works that focus on the impact of technological innovation on achieving sustainable development goals and employment opportunities. Specially, it emerges as a matter of concern for the nations in the post-COVID19 era. In this context, an investigation into the dual socio-environmental effect of technological innovation for multiple countries over a longer period can facilitate efficient decision-making of policymakers. It acts as the main motivation of the study. To the best of knowledge, this is the first work that investigates the effect of technological innovations on SDGs and employment in the COVID-19 pandemic era. The summary of the relevant literature and contribution of this work is presented in Table 1. It shows the gap that this study aims to fill as the first study with dataset from 100 countries analyzing impact of innovation on sustainability and employment. None of the other studies in this field relies on the dataset of this size, and they also do not attempt to balance the impact of innovation on sustainability and employment.

\section{Model and methods}

\subsection{Problem description}

As the resistance to shift from the existing energy sources to renewable ones creates deterrence into the transition, environmental quality might not start improving immediately with the rise in technological innovation. Therefore, during the initial phases of innovation, environmental degradation might not start getting reduced. However, gradual diffusion of innovation and achieving economies of scale gradually bring down the cost of these solutions, leading to their rising acceptability. This can bring forth a steady decline in the growth of environmental degradation.

At the same time, the development and deployment of these solutions require skilled and unskilled labor, which eventually creates employment in the economy. Being capitalintensive, once these solutions are deployed, they start replacing human labor. Hence, the existing systems can be more efficient. Following Arrow et al. (1961), this replacement of labor with technology (capital) creates unemployment within the economy.

This dual impact of technological innovation might be catalyzed by the structural transformation of the economy, i.e. more service-orientation of the sectoral activities might increase unemployment, while environmental degradation might fall. On the contrary, manufacturing-oriented sectoral transformation might experience an opposite effect. Moreover, energy usage patterns might also have a moderating impact on the impact duality of innovation. As the energy-intensive production practices are more inclined toward being stemmed from the manufacturing sector, higher usage of fossil fuel might have coexistence with higher employment. Moreover, the channel of international trade is also utilized to transfer the old and dirtier technologies to comparatively poorer and less developed countries for controlling the carbon footprint. Also, the transfer of greener technologies to host countries might boost innovation capabilities, which might have a consequence on environmental quality and unemployment. This impact of the globalization channel can be explained by the "Pollution Haven hypothesis" (Levinson and Taylor, 2008) and the "Pollution Halo hypothesis" (Antweiler et al., 2001). Lastly, the developmental trajectory of a nation needs to account for the balance between demand and supply of labor. 
JEIM 35,1

300

Here, population growth can emerge as a crucial factor. If the population growth is higher than the demand of labor, the country is likely to suffer from the unemployment problem. Moreover, this incidence of unemployment might lead to income inequality and deterioration in living standards. This might add to the environmental degradation arising out of the unsustainable energy usage pattern.

\subsection{Empirical model}

Assessing the impact of technological innovation on environmental quality and unemployment entails considering a theoretical framework that can capture the evolutionary impact of technological innovation across a group of countries that may represent a wide set of innovation and enterprise-level beliefs. Hence, the present study embarks on the EKC hypothesis framework. According to the seminal work of Grossman and Kruger (1991), environmental degradation starts rising during the early phase of economic growth. Once this economic growth reaches a threshold, improvement in the living standard raises environmental awareness among citizens. Henceforth, further growth in the economy leads to a decline in the environmental degradation. Quadratic specification of this hypothesis results in an inverted $U$-shaped association between environmental degradation and (drivers of) economic growth. This hypothesis is capable of revealing the nonlinear evolutionary impact of policy instruments on a target policy parameter for a pool of countries (Shahbaz and Sinha, 2019). The empirical schema of this association can be represented as follows:

$$
Y_{i, t}=\beta_{0}+\beta_{1} \mathrm{TECH}_{i, t}+\beta_{2} \mathrm{TECH}_{i, t}^{2}+X_{i, t}
$$

where,

$Y=\left\{\begin{array}{l}\mathrm{CO}_{2} \text { emissions } \\ \text { Unemployment }\end{array}\right.$

TECH $=$ Proxy for technological innovation;

$X=$ Matrix of other explanatory variables;

$i=$ Sample countries; and

$t=$ Sample years, $\beta_{0}, \beta_{1}, \beta_{2} \neq 0$.

Now, first-order differentiation of equation(1) with respect to TECH. and corresponding firstorder condition (FOC) determine the optimum point of the association, described in equation (2):

$$
\begin{aligned}
& \frac{\partial Y_{i, t}}{\partial \mathrm{TECH}_{i, t}}=\beta_{1}+2 \beta_{2} \mathrm{TECH}_{i, t}=0 \\
& \mathrm{TECH}_{i, t}=-\beta_{1} / 2 \beta_{2}
\end{aligned}
$$

Now, given the two conflicting policy agendas, the shape of this association can take two different forms, based on the two dependent variables. This association is expected to follow a generally accepted inverted $U$-shaped form for $\mathrm{CO}_{2}$ emissions. Therefore, in this case, $\beta_{1}>0$ and $\beta_{2}<0$. On the other hand, the shape is expected to be $U$-shaped for unemployment. Hence, in this case, $\beta_{1}<0$ and $\beta_{2}>0$. For both the cases, the turnaround points of the association can be expressed as $\frac{-\beta_{1}}{2 \beta_{2}}$ presented in equation (2). However, interpretation of this point is different for both the cases. It denotes the maximum of and the minimum of the association for $\mathrm{CO}_{2}$ emissions and unemployment, respectively. This can be shown by the second-order differentiation of equation (1) with respect to TECH. 


$$
\frac{\partial^{2} Y_{i, t}}{\partial \mathrm{TECH}_{i, t}^{2}}=\left\{\begin{array}{cc}
2 \beta_{2}<0, & \text { for } \mathrm{CO}_{2} \text { emissions } \\
2 \beta_{2}>0, & \text { for Unemployment }
\end{array}\right.
$$

Now, in empirical pursuit, equation(1) can be explained as per the following:

$$
\begin{gathered}
\mathrm{CE}_{i, t}=\alpha_{0}+\alpha_{1} \mathrm{TFP}_{i, t}+\alpha_{2} \mathrm{TFP}_{i, t}^{2}+\alpha_{3} \mathrm{GLOB}_{i, t}+\alpha_{4} \mathrm{EU}_{i, t}+\alpha_{5} \mathrm{POP}_{i, t}+\alpha_{6} \mathrm{STR}_{i, t} \\
\mathrm{UE}_{i, t}=\gamma_{0}+\gamma_{1} \mathrm{TFP}_{i, t}+\gamma_{2} \mathrm{TFP}_{i, t}^{2}+\gamma_{3} \mathrm{GLOB}_{i, t}+\gamma_{4} \mathrm{EU}_{i, t}+\gamma_{5} \mathrm{POP}_{i, t}+\gamma_{6} \mathrm{STR}_{i, t}
\end{gathered}
$$

The description of the dependent and independent variables presented in equations (3) and (4) are expressed as follows:

(1) $\mathrm{CE}=\mathrm{CO}_{2}$ emissions;

(2) $\mathrm{UE}=$ Unemployment;

(3) TFP = Total factor productivity;

(4) $\mathrm{GLOB}=$ Globalization;

(5) $\mathrm{POP}=$ Population; and

(6) $\mathrm{STR}=$ Structural transformation of economy.

As the investment in research and development might not be realized fully in the innovation output, the output indicator of innovation can be helpful to capture the effects of innovation. For this reason, in this study, TFP, an output indicator of innovation, is selected. STR is determined by the Lilien Index (Lilien, 1982), which measures the changes in labor share across primary, secondary and tertiary sectors. It can be represented as follows:

$$
\mathrm{STR}_{i, t}=\sqrt{\sum_{s=1}^{3}\left(\frac{\mathrm{SE}_{s, t}}{\mathrm{SE}_{t}}\right)\left(\Delta \log \mathrm{SE}_{s, t}-\Delta \log \mathrm{SE}_{t}\right)^{2}}
$$

where,

SE: Employment share in a particular sector; and

$s=1,2,3$ : primary, secondary and tertiary sector, respectively.

\subsection{Methods}

3.3.1 Cross-sectional dependence test. The examination of $\mathrm{CD}$ in the panel data is of utmost importance, as the same might produce biased and inconsistent results (Phillips and Sul, 2003). Usually, the countries are connected via different channels such as economic, social, political, bilateral trade and board sharing. These forms of associativity among the countries might result in $\mathrm{CD}$ among the model variables. For this reason, the CD test (Chudik and Pesaran, 2015) is applied to examine the presence of $\mathrm{CD}$ in the data. The $\mathrm{CD}$ can be measured as follows:

$$
\mathrm{CD}=\sqrt{\frac{2 T}{N(N-1)}}\left\{\sum_{i=0}^{N-1} \sum_{j=i+1}^{N} \rho_{i j}\right\}
$$


JEIM 35,1

where

$$
\begin{aligned}
N & =\text { Cross-sections in panel; } \\
T & =\text { represents the time span; and } \\
\rho_{i j} & =\text { correlation coefficient of unit } i \text { and } j .
\end{aligned}
$$

Under the null hypothesis of weak $\mathrm{CD}$, it is assumed that the statistic is asymptotically distributed.

3.3.2 Unit root test. After observing the inter-country association, it is important to test whether the series are stable in the long run. For this purpose, the cross-sectional augmented Dickey-Fuller (i.e. CADF) (Pesaran, 2007) econometric approach has been adopted. This newgeneration procedure helps to establish the integration order. Equation (7) exhibits the calculation procedure of this test where $\nu$ and $z$ signify the lag-size and time-based mean interdependency, respectively.

$$
\Delta z_{i, t}=\lambda_{i}+\beta_{i} z_{i, t-1}+\Phi_{i \underline{z_{t-1}}}+\sum_{l=0}^{\nu} \gamma_{i, l} \Delta \underline{z_{i t-1}}+\sum_{l=0}^{\nu} \zeta_{i, l} z_{i, t-1}+\underline{\epsilon}_{i, t}
$$

This procedure generates the $t$-statistics by using the distinct ADF value. Based on the calculated values of this test, the cross-sectional Im-Pesaran-Shin test (CIPS) (Pesaran, 2007) provides the individually treated values based on the cross-country treatment. The expression presented in equation(8) generates the CIPS test results.

$$
\text { CIPS test value }=\left(\frac{1}{\mathrm{NC}}\right) \sum_{i=1}^{\mathrm{NC}} t_{i}(\mathrm{NC}, \mathrm{RP})
$$

3.3.3 Cointegration test. By considering the possible CD, Westerlund (2007) proposes a unique methodology to establish the long-run association between the variables. This test calculates the error correction value and generates the four cross-section-based values. Here, the significant values ascertain that the series are cointegrated and apt for the long-run examination. On the other hand, the acceptance of the null hypothesis signifies that the longrun cointegration among the series is missing. Equation (9) presents the Westerlund test values.

$$
\Delta W_{i, t}=\Phi_{i} k_{t}+\alpha_{i} W_{i, t-1}+\lambda_{i} D_{i, t-1}+\sum_{l=1}^{\nu_{i}} \alpha_{i, l} \Delta W_{i, t-l}+\sum_{l=-q_{i}}^{\nu_{i}} \rho_{i, l} D_{i, t-1}+\underline{\epsilon}_{i, t}
$$

Here, $k_{t}$, and $\alpha_{i}$ represent the constant term and adjustment speed, respectively. Also, the combinations of constant and trend, i.e. $\Phi_{i} k_{t}$, are considered to represent the constant term. Pesaran (2006) presents a distinct solution technique to handle this mutual dependency, which can help in generating reliable results. The error term can be calculated by using the unobserved matrix (UFM) of the given factors, presented in equation(10):

$$
\epsilon_{i t}=\Phi_{i} \mathrm{UFM}_{t}+\underline{\epsilon}_{i, t}
$$

By using the averages of the mutually dependent factors, the UFM will be calculated, which may efficiently handle the possible inter-dependency.

\subsection{Data}

The study is conducted for 100 countries over 1991-2019. These countries are segregated into four different income categories (i.e. low, lower-middle, upper-middle and high), following the 
categorization provided by the World Bank (Serajuddin and Hamadeh, 2020). To get the detailed description, refer to Table A1 in Appendix. The data for TFP have been obtained from Penn World Table 10.0. The data for $\mathrm{CO}_{2}$ emissions (in metric tons per capita), population (total), unemployment (\% of the total labor force), energy use (kg of oil equivalent per capita), the labor force (total) and the number of labors in three sectors (agricultural, industrial and service) have been collected from the World Development Indicators (World Bank, 2021). The data for globalization have been taken from the KOF database (Gygli et al., 2019). Except STR (structural transformation of economy), all the variables are logtransformed before analysis.

While talking about the sample selection for this study, it is worthwhile to observe that the temporal span of the study refers to the pre-COVID-19 period, whereas the objective of the study is aimed at the post-COVID-19 period. Though this selection might appear to be speculative, there are some definite reasons behind this informed choice of sample. First, because of the ongoing technological innovations, the world already started experiencing betterment in environmental quality. Slowdown in manufacturing and other anthropogenic activities due to the incidence of COVID-19 only accelerated the process. Hence, it can be said that the COVID-19 outbreak complemented the environmental benefits of technological innovations, without causing any significant transformations in the environmental impact of innovations. Second, Industry 4.0 has been gradually creating unemployment across the manufacturing firms, and literature has cited its evidence (Kovacs, 2018). The convergence in the employment rate during the Industry 4.0 regime indicates the slowdown in job creation process (Gashenko et al., 2020). This slowdown in the job creation was catalyzed by the slowdown in manufacturing and other anthropogenic activities due to the incidence of COVID-19 outbreak. Hence, the COVID-19 outbreak is said to be complemented the social detriment of technological innovations, without causing any significant transformations in the social impact of innovations. As the COVID-19 outbreak did not bring any transformations in the socio-ecological impacts of innovations, and the nature of COVID19 only intensified those impacts, hence consideration of this particular pre-COVID-19 data to prescribe the post-COVID-19 policy framework is logical.

Lastly, it is also assumed that the impact of innovation might vary according to the level of development. Hence, focusing on a single country or a group of homogenous countries might not properly demonstrate the socio-ecological impacts of technological innovation. Moreover, the development and deployment of innovative solutions depend largely on the position of a country on a developmental trajectory. Hence, analyzing this impact for the countries across several levels of income might indicate how the socio-ecological impacts of technological innovation might change with levels of development.

\section{Analysis of outcomes}

\subsection{Analysis of country groups}

The analysis of the model outcomes starts with the baseline estimation derived from adopting the Least Squares Dummy Variable (LSDV) approach, and the model outcomes are reported in Tables 2 and 3. These outcomes are estimated for the countries of four income groups classified by the World Bank. First, the results of the long-run coefficient estimation for $\mathrm{CO}_{2}$ emissions are discussed. The model outcomes reported in Table 2 for all the four groups of countries show that the $\mathrm{CO}_{2}$ emissions-TFP associations resemble the generally accepted inverted- $U$-shaped form of EKC. Now, it is worthwhile noting that except for the case of highincome countries, the turnaround points are outside the sample range. This indicates that though the prevailing economic growth trajectory is increasing the $\mathrm{CO}_{2}$ emissions, the growth rate of emission is decreasing, and the turnaround points will be achieved during the post-COVID period. This shows that the innovation-led economic growth trajectory being trodden by these nations is pro-environmental. Also, the turnaround point for low-income
Innovational duality and sustainable development

303 


\begin{tabular}{|c|c|c|c|c|c|}
\hline $\begin{array}{l}\text { JEIM } \\
35,1\end{array}$ & Variables & Low income & $\begin{array}{l}\text { Lower-middle } \\
\text { income }\end{array}$ & $\begin{array}{l}\text { Upper-middle } \\
\text { income }\end{array}$ & High income \\
\hline \multirow[b]{5}{*}{304} & TFP & $1.424 * * *[0.904]$ & 1.562 *** $[0.176]$ & $1.575 *[0.097]$ & $1.104 * *[0.186]$ \\
\hline & $(\mathrm{TFP})^{2}$ & $-0.742 * * *[0.114]$ & $-1.019 *[0.182]$ & $-1.786 * *[0.177]$ & $-2.359 *[0.125]$ \\
\hline & GLOB & $2.212 * * *[0.626]$ & $0.613 * * *[0.166]$ & $0.231 * * *[0.072]$ & $-0.246 * * *[0.082]$ \\
\hline & $\mathrm{EU}$ & $1.191 * * *[0.158]$ & $1.343 * * *[0.053]$ & $1.142 * * *[0.013]$ & $0.877 * * *[0.015]$ \\
\hline & POP & $0.578 * * *[0.192]$ & $0.3408 * * *[0.021]$ & $0.048 * * *[0.007]$ & $0.049 * * *[0.007]$ \\
\hline & STR & $0.329[0.379]$ & $1.0185 * * *[0.250]$ & $-0.253 * *[0.117]$ & $-0.269 * *[0.118]$ \\
\hline \multirow{6}{*}{$\begin{array}{l}\text { Table } 2 \text {. } \\
\text { LSDV estimates of } \mathrm{CO}_{2} \\
\text { emissions for the } \\
\text { income-wise } \\
\text { segregated countries }\end{array}$} & Shape of curve & Inverted $U$-shaped & Inverted $U$-shaped & Inverted $U$-shaped & Inverted $U$-shaped \\
\hline & $\begin{array}{l}\text { Turnaround } \\
\text { point }\end{array}$ & 2.61 & 2.15 & 1.55 & 1.26 \\
\hline & Year dummies & Yes & Yes & Yes & Yes \\
\hline & Observations & 145 & 696 & 812 & 1,247 \\
\hline & $R^{2}$ & 0.64 & 0.57 & 0.85 & 0.74 \\
\hline & \multicolumn{5}{|c|}{ Note(s): $* * *$ Signifies $p$-value $<0.01, * * 0.01 \leq p$-value $<0.05, * 0.05 \leq p$-value $<0.10$} \\
\hline
\end{tabular}

Table 3.

LSDV estimates of unemployment for the income-wise segregated countries

\begin{tabular}{|c|c|c|c|c|}
\hline Variables & Low income & Lower-middle income & Upper-middle income & High income \\
\hline TFP & $-3.875^{* * *}[1.334]$ & $-1.058^{* * *}[0.145]$ & -0.791 *** $[0.202]$ & $-0.183^{*}[0.011]$ \\
\hline$(\mathrm{TFP})^{2}$ & $1.557 * * *[0.581]$ & $0.679 * * *[0.076]$ & $1.128 *[0.164]$ & $0.317 * *[0.014]$ \\
\hline GLOB & $-1.929 * *[0.924]$ & $1.762 * * *[0.137]$ & $0.7461 * * *[0.149]$ & $1.207 * * *[0.139]$ \\
\hline $\mathrm{EU}$ & $-1.072^{* * *}[0.233]$ & $-0.159 * * *[0.044]$ & $-0.332 * * * ; 0.046]$ & $-0.511 * * *[0.025]$ \\
\hline POP & $0.190 * * *[0.084]$ & $0.098[0.017]$ & $0.192 * * *[0.013]$ & $0.071 * * *[0.011]$ \\
\hline STR & $-0.538[0.382]$ & $-1.033^{* *}[0.206]$ & $0.671 * * *[0.244]$ & $0.273[0.199]$ \\
\hline Shape of curve & $U$-shaped & $U$-shaped & $U$-shaped & $U$-shaped \\
\hline Turnaround point & 3.47 & 2.18 & 1.42 & 1.33 \\
\hline Year dummies & Yes & Yes & Yes & Yes \\
\hline Observations & 145 & 696 & 812 & 1,247 \\
\hline$R^{2}$ & 0.54 & 0.56 & 0.63 & 0.73 \\
\hline
\end{tabular}

Note(s): Standard errors are within parentheses [, ${ }^{* * *}$ signifies $p$-value $<0.01, * * 0.01 \leq p$-value $<0.05$, $* 0.05 \leq p$-value $<0.10$

countries is the highest, followed by the ones of lower- and upper-middle-income countries. This gives a comparative scenario between the prevailing policies in these countries. With the rise in income level, policymakers strive to transform the existing policies from pro-growth to pro-development. This distinction among the economic policies in these four groups of countries is revealed through the nature of turnaround points. While all these countries depend on the innovation processes, it might be possible that the development of the innovation capabilities is not ingenious. Hence, the innovative solutions might be imported. Also, it is found that the impact of globalization on $\mathrm{CO}_{2}$ emissions is positive, except for highincome countries. The highest impact is observed in the case of low-income countries, followed by the lower- and upper-middle-income countries. This scenario can be traced back to the "Pollution Haven hypothesis," i.e. the high-income countries try to reduce their environmental degradation by exporting the low-cost polluting technologies to the countries with a lower level of income. For this reason, it is expected that the impact of globalization on $\mathrm{CO}_{2}$ emissions might be negative for the high-income countries, and the study outcome is consistent with this phenomenon. Now, once these technologies are employed in the production, commercial electricity is required to run these solutions. As the fossil fuel-based energy solutions remain the predominant source of energy across the majority of the 
countries, it is expected that the energy usage patterns will have negative environmental consequences. The present study outcome reflects the same. However, the negative environmental impact has been observed the highest and lowest for the low- and high-income countries, respectively. This situation might have arisen due to the highest and lowest share of renewable energy solutions in the energy mix of the high- and low-income countries, respectively. Apart from the energy usage pattern in the industries, the domestic energy demand also caters to the end-energy use, leading to $\mathrm{CO}_{2}$ emissions. Hence, the impact of population on $\mathrm{CO}_{2}$ emissions is expected to be positive, and the study outcomes also reveal the same phenomenon. However, it is noteworthy to observe that the impact is highest in the case of the low-income countries and lowest for the upper-middle- and high-income countries. This situation can be attributed to the population growth characteristics of these nations, i.e. the low-income countries have the highest population growth, whereas it is lowest for the upper-middle- and high-income countries.

The structural transformation of the economy exhibits a positive impact on the $\mathrm{CO}_{2}$ emissions for the low-, lower-middle- and upper-middle-income countries. On the contrary, the effect is negative in high-income countries. This finding can be traced back to the impact of economic growth patterns on environmental degradation, and thereby, substantiating the policy void existing in the low-, lower-middle- and upper-middle income countries from the perspective of achieving environmental sustainability. This is an area where policy intervention might be necessary for these countries to make progress toward achieving the Agenda 2030.

After the $\mathrm{CO}_{2}$ emissions-economic growth association, the unemployment-economic growth association is discussed. The model outcomes reported in Table 3 for all the four groups show that the unemployment-TFP associations depict a $U$-shaped form. This segment of the results reveals that unemployment first shrinks with the rise in innovation-led economic growth and starts increasing after reaching a threshold. In a similar fashion with the previous case, it is observed that the turnaround point for low-income countries is the highest, followed by the ones of lower-middle-, upper-middle- and high-income countries. The comparative analysis between the prevailing policies in these countries signifies that the turnaround points remain outside the sample range for all four cases. It indicates that the economic growth trajectory trodden by these countries can perhaps give rise to the issue of unemployment during the post-COVID period. When this finding is analyzed along with the previous segment of estimation results for $\mathrm{CO}_{2}$ emissions, a policy paradox is encountered. When the innovation-led economic growth trajectory is expected to bring environmental sustainability, the same growth trajectory compels these countries to depart from achieving social sustainability. This scenario can be analyzed further by incorporating the impacts of other explanatory variables. For low-income countries, the majority of the economic activities can be categorized as labor-intensive and manufacturing-oriented. Given the innovation capacity being comparatively less than the countries in the other three income categories, increasing economic activities raise the demand for additional labor. Now, this demand might fall at a later stage with the rise in innovation capacity. For the countries of other income categories, this situation might arise comparatively sooner, as the innovation capacity of these nations is higher than those of the countries under the low-income category. Therefore, the channel of globalization utilized by the low-income countries might help in increasing manufacturing activities. On the other hand, the countries under the other income groups might utilize this channel for boosting their innovation capacity through technology transfer. Hence, globalization might exert negative social externalities for the latter group of countries by creating unemployment, whereas boosting manufacturing activities in the low-income countries might reduce unemployment by extending the labor-intensive manufacturing activities. This situation might be traced back to the classic case of "Capital-labor substitution" demonstrated by Arrow et al. (1961). The model outcomes validate this
Innovational duality and sustainable development

305 
JEIM 35,1

306

argument. Now, the impact of energy usage patterns might substantiate this insight by the elasticity values. The coefficient of energy usage is highest for the low-income countries, whereas the impacts are comparatively lower for the other three groups of countries. It exhibits that the impact of energy use is diminishing in the countries with higher income levels, as the impact of innovation might be reflected through the energy efficiency and share of renewable energy in the energy mix of these countries. From another dimension, investigating this scenario from the perspective of the labor market, it can be opined that given ceteris paribus, a higher population might create an excess supply of labor. As a result, the unemployment situation can be aggravated. Also, the model outcomes suggest that this argument might be valid for all the four groups of countries, while the impact is the lowest for the high-income countries. When these scenarios are analyzed together, the impact can be observed in terms of the structural transformation of the economy, which functions in the intersection of product/service and labor market. In the era of Industry 4.0, the transformation of economies toward being service-oriented might open up avenues for innovations. Also, the advent of automation technologies might start replacing human labor. On the contrary, raising the traditional labor-intensive manufacturing processes shrink the innovation opportunity and eventually reduces the potential unemployment possibilities. The first half of this argument is substantiated by the model outcomes for upper-middle- and high-income countries, whereas the latter half of this argument is validated by the model outcomes for lowand lower-middle-income countries. Finally, the estimation outcomes of the model reveal that the innovation-led economic growth might lead these nations toward being socially unsustainable. As a result, the countries might experience a hindrance in attaining the objectives of Agenda 2030.

\subsection{Robustness check with second-generation methods}

In a globalized world, it might be possible that the countries might be connected via economic spillovers. Therefore, these associations cause the interdependency between economic growth drivers of different countries. This dependence leads to a specific estimation issue, i.e. $\mathrm{CD}$. In the presence of $\mathrm{CD}$, the second-generation methodological approach should be adopted. Driven by this estimation agenda, first, the possibilities of CD and slope heterogeneity are checked in the data. The test outcomes reported in Table 4 suggest the presence of $\mathrm{CD}$ and panel heterogeneity in data. Hence, this evidence warrants the application of the second-generation methodological approach.

\begin{tabular}{|c|c|c|c|c|c|}
\hline & Low income & Lower-middle income & Upper-middle income & High income & All \\
\hline \multicolumn{6}{|l|}{ CD test } \\
\hline $\mathrm{CE}$ & $16.202^{* * *}$ & $6.482^{* * *}$ & $74.100 * * *$ & $159.836 * * *$ & $127.654 * * *$ \\
\hline UE & $11.747 * * *$ & $79.219 * * *$ & $96.868 * * *$ & $143.529 * * *$ & $336.583 * * *$ \\
\hline TFP & $16.370 * * *$ & $75.558^{* * * *}$ & $93.758 * * *$ & $116.188^{* * *}$ & $302.892^{* * * *}$ \\
\hline LGLOB & $17.024 * * *$ & 89.440 *** & $104.668 * * *$ & $161.795 * * *$ & $378.772 * * *$ \\
\hline $\mathrm{EU}$ & $17.019 * * *$ & $89.424^{* * * *}$ & $104.647 * * *$ & $161.783 * * *$ & $378.715^{* * * *}$ \\
\hline POP & $17.029 * * *$ & $89.463^{* * *}$ & $104.697 * * *$ & $161.813^{* * *}$ & $378.861 * * *$ \\
\hline STR & $13.146^{* * * *}$ & $61.613^{* * *}$ & $72.461 * * *$ & $115.741^{* * * *}$ & $261.392 * * *$ \\
\hline \multicolumn{6}{|c|}{ Slope heterogeneity test } \\
\hline Statistics (1) & $6.852 * * *$ & $17.139 * * *$ & $15.470 * * *$ & $25.193^{* * *}$ & $35.371 * * *$ \\
\hline Statistics (2) & $7.590 * * *$ & $21.493 * * *$ & $18.524 * * *$ & $31.520 * * *$ & $47.039 * * *$ \\
\hline
\end{tabular}

Table 4.

CD test outcomes

Note(s): ***Signifies $p$-value $<0.01$, statistics (1): by adding cross-sectional averages of $\mathrm{CO}_{2}$ Statistics (2): by adding AR (1) process 
The $\mathrm{CD}$ in the data necessitates the incorporation of second-generation panel diagnostic tests for long-run coefficient estimation. The second-generation panel unit root test is conducted to understand the order of the integration among the model parameters. The results reported in Table 5 show that the model parameters to be integrated to the first order. Based on the confirmation of order of integration among the model parameters, the confirmation of long-run association among them is validated through the second-generation panel cointegration test. The results reported in Table 6 demonstrate that the model parameters to be cointegrated, and this segment of the findings warrants the estimation of long-run coefficients.

To accommodate the $\mathrm{CD}$ in the data, two alternative methodological approaches, i.e. crosssection augmented distributed lag (CS-DL) and dynamic common correlated effectaugmented generalized method of moments (DCCE-GMM), have been adopted. The results of the model estimations using these two methods are provided in Tables 7 and 8. For both the models, the coefficients and corresponding turnaround points demonstrate similar patterns compared to the LSDV estimation results. These model outcomes using second-generation long-run coefficient estimation methods exhibit that the prevailing policy outcomes do not undergo any changes even in the presence of economic spillovers among the nations. Hence, it can be deduced that the model estimates derived by the LSDV method are robust, and the policy-level problems highlighted by the model outcomes are prevalent, irrespective of the economic connectedness among the nations.

\begin{tabular}{lllll}
\hline Low income & Lower-middle income & Upper-middle income & High income & All \\
\hline
\end{tabular}

\section{Cross-sectional augmented Im, Pesaran and Shin test}

$\begin{array}{llll}\text { CE } & -1.691 & -2.041 & -2.502 \\ \Delta \mathrm{CE} & -5.120^{* * *} & -5.150^{* * * *} & -5.019^{* * *} \\ \text { UE } & -1.588 & -1.537 & -2.055 \\ \Delta \mathrm{UE} & -3.688^{* * *} & -4.353^{* * * *} & -4.388^{* * *} \\ \text { TFP } & -1.469 & -1.278 & -1.508 \\ \Delta \text { TFP } & -3.853^{* * *} & -4.348^{* * * *} & -4.539^{* * *} \\ \text { LGLOB } & -1.412 & -1.787 & -1.705 \\ \Delta \text { LGLOB } & -4.593^{* * *} & -4.910^{* * * *} & -5.441^{* * *} \\ \text { EU } & -1.671 & -2.196 & -2.456 \\ \Delta \text { EU } & -4.794^{* * *} & -4.936^{* * * *} & -5.095^{* *} \\ \text { POP } & -1.994 & -1.355 & -0.871 \\ \Delta \text { POP } & -3.938^{* * *} & -3.752^{* * * *} & -2.214^{* * *} \\ \text { STR } & -0.981 & -1.152 & -1.742 \\ \Delta \text { STR } & -5.493^{* * *} & -5.714^{* * * *} & -6.028^{* * *} \\ \text { Note(s): } & & & \end{array}$

Note(s): ***Signifies $p$-value $<0.01 ; * *$ Signifies $0.01<p$-value $<0.05$
Innovational duality and sustainable development

\section{7}




\section{JEIM 35,1}

Table 7.

Robust estimates of $\mathrm{CO}_{2}$ emissions for the income-wise segregated countries

\begin{tabular}{|c|c|c|c|c|}
\hline & Low income & $\begin{array}{l}\text { Lower-middle } \\
\text { income }\end{array}$ & $\begin{array}{l}\text { Upper-middle } \\
\text { income }\end{array}$ & High income \\
\hline \multicolumn{5}{|l|}{$C S-D L$} \\
\hline TFP & $5.633 *[1.015]$ & $2.870^{* *}[1.174]$ & $0.644^{* *}[0.189]$ & $0.156[0.331]$ \\
\hline$(\mathrm{TFP})^{2}$ & $-2.624 * *[0.927]$ & $-2.196 *[1.137]$ & $-0.869 * * *[0.174]$ & $-0.713 * * *[0.169]$ \\
\hline GLOB & $0.849 *[0.306]$ & $0.417 * *[0.034]$ & $0.458 * *[0.216]$ & $-0.352[0.288]$ \\
\hline $\mathrm{EU}$ & $0.528 * *[0.267]$ & $0.755^{* * *}[0.161]$ & $0.827 * * *[0.141]$ & $0.989 * * *[0.071]$ \\
\hline POP & $0.257[0.350]$ & $0.153 * *[0.024]$ & $0.425 * * *[0.159]$ & $0.434 * *[0.215]$ \\
\hline STR & $0.101[0.617]$ & $0.785^{*}[0.008]$ & $-0.711 *[0.125]$ & $-1.109 * * *[0.046]$ \\
\hline Shape of curve & Inverted $U$-shaped & Inverted $U$-shaped & Inverted $U$-shaped & Inverted $U$-shaped \\
\hline Turnaround point & 2.93 & 1.92 & 1.45 & 1.12 \\
\hline Observations & 140 & 672 & 812 & 1,247 \\
\hline$R^{2}$ & 0.74 & 0.79 & 0.84 & 0.81 \\
\hline \multicolumn{5}{|c|}{ Common correlated effect-augmented GMM } \\
\hline TFP & $2.914^{* * * *}[0.783]$ & $1.768^{* *}[0.545]$ & $0.501[0.452]$ & $0.935 * *[0.148]$ \\
\hline$(\mathrm{TFP})^{2}$ & $-1.516 * * *[0.606]$ & $-1.439 *[0.367]$ & $-0.685 * *[0.109]$ & $-2.152 * * *[0.711]$ \\
\hline GLOB & $0.521 *[0.045]$ & $1.465 * *[0.490]$ & $0.346[0.495]$ & $-1.208[0.489]$ \\
\hline $\mathrm{EU}$ & $2.845^{* *}[0.813]$ & $1.444 * * *[0.386]$ & $0.809 * * * * 0.271]$ & $0.692 * * *[0.134]$ \\
\hline POP & $3.757 * * *[1.353]$ & $1.522 *[0.709]$ & $0.954[0.156]$ & $0.271[0.907]$ \\
\hline STR & $0.123[0.457]$ & $0.536 *[0.151]$ & $-0.747 * *[0.128]$ & $-1.236 * * *[0.154]$ \\
\hline Shape of curve & Inverted $U$-shaped & Inverted $U$-shaped & Inverted $U$-shaped & Inverted $U$-shaped \\
\hline Turnaround point & 2.61 & 1.85 & 1.44 & 1.24 \\
\hline Observations & 130 & 624 & 728 & 1,118 \\
\hline${\text { Wald } \mathrm{chi}^{2}}$ & $12.21 * *$ & $18.42^{* * * *}$ & $46.15^{* * * *}$ & $30.78^{* * * *}$ \\
\hline Hansen-J $p$-value & 0.663 & 0.210 & 0.684 & 0.421 \\
\hline Wooldridge & 0.798 & 0.568 & 0.267 & 0.557 \\
\hline
\end{tabular}

$p$-value

Note(s): Standard errors are within parentheses [, $* * *$ Signifies $p$-value $<0.01, * * 0.01 \leq p$-value $<0.05$, $* 0.05 \leq p$-value $<0.10$

\subsection{Analysis of full sample}

In this subsection, finally, the estimation for the entire sample is conducted using LSDV, CSDL and DCCE-GMM methods. The estimation results are reported in Tables 9 and 10. The model outcomes reported in Table 9 signify that the $\mathrm{CO}_{2}$ emissions-TFP association resembles the generally accepted inverted- $U$-shaped form of EKC for all three methods. This outcome extends the findings of Amri et al. (2019) for Tunisia and Wang et al. (2019) for China. Now, the turnaround point of this association reveals a generalized tendency of the economic growth trajectory being trodden by all the countries at large. The turnaround point within the sample range shows that the countries are largely treading on an environmentally sustainable economic growth path. Therefore, it can be assumed that during the post-COVID period, the prevailing innovation-led economic growth patterns will help the nations to achieve a lower rate of $\mathrm{CO}_{2}$ emissions, signifying sturdy progress toward the attainment of SDG 13, i.e. climate action. This particular segment of the findings is corroborated by the impact of structural transformation of the economy on $\mathrm{CO}_{2}$ emissions. Driven by innovation, the active economic sectors exhibit a higher inclination toward the service sector. This sectoral shift from manufacturing activities reduces the environmental pressure by reducing the $\mathrm{CO}_{2}$ emissions in the ambient atmosphere. This outcome corroborates the finding of du Can and Price (2008). This structural transformation of the economy is complemented by the globalization pattern, which is characterized by the cross-border transfer of clean technologies. This internalization of negative environmental externality by the 


\begin{tabular}{|c|c|c|c|c|}
\hline & Low income & $\begin{array}{l}\text { Lower middle } \\
\text { income }\end{array}$ & $\begin{array}{l}\text { Upper middle } \\
\text { income }\end{array}$ & High income \\
\hline \multicolumn{5}{|l|}{$C S-D L$} \\
\hline TFP & $-10.326^{*}[5.832]$ & $-2.298 * * *[0.134]$ & $-1.394 *[0.204]$ & $-5.104 * * *[1.837]$ \\
\hline$(\mathrm{TFP})^{2}$ & $4.510 * *[0.936]$ & $1.483 * *[0.019]$ & $1.825 * *[0.158]$ & $7.917 *[1.389]$ \\
\hline GLOB & $-0.789 * * *[0.186]$ & $0.611 *[0.178]$ & $0.171[0.467]$ & $0.502 * *[0.054]$ \\
\hline $\mathrm{EU}$ & $-0.436[0.301]$ & $-0.891 * * *[0.082]$ & $-0.752 * * *[0.264]$ & $-0.487 *[0.276]$ \\
\hline POP & $0.914[0.322]$ & $0.648[0.197]$ & $0.836^{* *}[0.377]$ & $0.644[0.586]$ \\
\hline STR & $-4.2463^{* *}[0.695]$ & $-1.384 *[0.334]$ & $1.631^{* * * *}[0.196]$ & $0.308 *[0.166]$ \\
\hline Shape of curve & $U$-shaped & $U$-shaped & $U$-shaped & $U$-shaped \\
\hline Turnaround point & 3.14 & 2.17 & 1.47 & 1.38 \\
\hline Observations & 140 & 696 & 812 & 1,247 \\
\hline$R^{2}$ & 0.77 & 0.84 & 0.83 & 0.86 \\
\hline \multicolumn{5}{|c|}{ Common correlated effect-augmented GMM } \\
\hline TFP & $-5.126^{* * *}[0.146]$ & $-2.016^{*}[0.817]$ & $-1.763 * *[0.849]$ & $-1.114 * * *[0.395]$ \\
\hline$(\mathrm{TFP})^{2}$ & $2.111 * * *[0.497]$ & $0.986 * *[0.127]$ & $1.318^{* * *}[0.059]$ & $1.923 * * *[0.207]$ \\
\hline GLOB & $-0.729 * * *[0.057]$ & $-2.547 *[0.169]$ & $1.914 * * * 0.766]$ & $2.055^{* *}[0.138]$ \\
\hline $\mathrm{EU}$ & $-4.107 *[1.862]$ & $-0.648 * * *[0.074]$ & $-0.764 *[0.180]$ & $-1.046 * * *[0.078]$ \\
\hline POP & $1.137[0.749]$ & $1.234 * *[0.177]$ & $0.533[0.812]$ & $1.966 *[0.884]$ \\
\hline STR & $-3.530 *[0.652]$ & $-0.671[0.906]$ & $1.534^{* *}[0.108]$ & $1.453^{* *}[0.323]$ \\
\hline Shape of curve & $U$-shaped & $U$-shaped & $U$-shaped & $U$-shaped \\
\hline Turnaround point & 3.37 & 2.78 & 1.95 & 1.34 \\
\hline Observations & 130 & 624 & 728 & 1,118 \\
\hline Wald chi ${ }^{2}$ & $9.83^{* *}$ & $18.80^{* * * *}$ & $33.30^{* * * *}$ & $18.28^{* * * *}$ \\
\hline Hansen-J $p$-value & 0.342 & 0.769 & 0.472 & 0.255 \\
\hline Wooldridge & 0.745 & 0.677 & 0.246 & 0.329 \\
\hline
\end{tabular}

Note(s): Standard errors are within parentheses [, $* * *$ signifies $p$-value $<0.01, * * 0.01 \leq p$-value $<0.05$, $* 0.05 \leq p$-value $<0.10$
Innovational duality and sustainable development

309

Table 8.

Robust estimates of unemployment for the income-wise segregated countries

\begin{tabular}{|c|c|c|c|}
\hline & LSDV & CS-DL & CCE-GMM \\
\hline TFP & $0.147 * *[0.070]$ & $0.163 * * * * 0.096]$ & $0.284 * * *[0.090]$ \\
\hline$(\mathrm{TFP})^{2}$ & $-0.314 * * *[0.042]$ & $-0.325^{* * *}[0.041]$ & $-0.614 * *[0.104]$ \\
\hline GLOB & $-0.316 * * *[0.061]$ & $-0.130 * *[0.063]$ & $-0.192[0.354]$ \\
\hline $\mathrm{EU}$ & $1.124 * * *[0.013]$ & $1.2624 * * *[0.235]$ & $0.752 * * *[0.163]$ \\
\hline POP & $0.061 * * *[0.006]$ & $0.113 * *[0.029]$ & $0.098 * *[0.017]$ \\
\hline STR & $-0.791 * * *[0.104]$ & $-0.866 *[0.150]$ & $-0.198 * *[0.028]$ \\
\hline Shape of curve & Inverted $U$-shaped & Inverted $U$-shaped & Inverted $U$-shaped \\
\hline Turnaround point & 1.26 & 1.29 & 1.26 \\
\hline Year dummies & Yes & - & - \\
\hline Group dummies & Yes & - & - \\
\hline Observations & 2,900 & 2,800 & 2,600 \\
\hline$R^{2}$ & 0.85 & 0.73 & - \\
\hline Wald $\operatorname{chi}^{2}$ & - & - & $22.77 * * *$ \\
\hline Hansen-J $p$-value & - & - & 0.639 \\
\hline Wooldridge $p$-value & - & - & 0.801 \\
\hline
\end{tabular}

Note(s): $* * *$ Signifies $p$-value $<0.01, * * 0.01 \leq p$-value $<0.05, * 0.05 \leq p$-value $<0.10$

Estimates of $\mathrm{CO}_{2}$ emissions for the all countries 


\begin{tabular}{|c|c|c|c|c|}
\hline \multirow{6}{*}{$\begin{array}{l}\text { JEIM } \\
35,1\end{array}$} & & LSDV & CS-DL & CCE-GMM \\
\hline & TFP & $-0.679 * * *[0.094]$ & $-1.589 * *[0.259]$ & $-0.829 *[0.166]$ \\
\hline & $(\mathrm{TFP})^{2}$ & $1.113^{* * *}[0.057]$ & $2.915 * *[0.638]$ & $1.503 * * *[0.067]$ \\
\hline & GLOB & $0.685^{* * *}[0.089]$ & $0.896[0.320]$ & $0.407 * *[0.196]$ \\
\hline & $\mathrm{EU}$ & $-0.153^{* * *}[0.021]$ & $-0.309 * *[0.056]$ & $-0.400 *[0.229]$ \\
\hline & POP & $0.122 *[0.008]$ & 0.766 *** $[0.049]$ & $0.632 *[0.117]$ \\
\hline \multirow{8}{*}{310} & STR & $-0.136^{* *}[0.017]$ & $-0.181 * *[0.048]$ & $-0.147^{* *}[0.012]$ \\
\hline & Shape of curve & $U$-shaped & $U$-shaped & $U$-shaped \\
\hline & Turnaround point & 1.36 & 1.31 & 1.32 \\
\hline & Year dummies & Yes & - & - \\
\hline & Group dummies & Yes & - & - \\
\hline & Observations & 2,900 & 2,800 & 2,600 \\
\hline & $R^{2}$ & 0.87 & 0.78 & - \\
\hline & Wald $\mathrm{chi}^{2}$ & - & - & $25.72^{* * * *}$ \\
\hline \multirow{2}{*}{$\begin{array}{l}\text { Table } 10 . \\
\text { Estimates of }\end{array}$} & Hansen-J $p$-value & - & - & 0.276 \\
\hline & Wooldridge $p$-value & - & - & 0.342 \\
\hline
\end{tabular}

Note(s): Standard errors are within parentheses [, $* * *$ signifies $p$-value $<0.01, * * 0.01 \leq p$-value $<0.05$, $* 0.05 \leq p$-value $<0.10$

globalization process is substantiated by the coefficient of globalization in the model outcomes. This outcome contradicts the finding of Sharif et al. (2020) for China. However, the prevailing energy usage patterns might cause a rise in the ambient $\mathrm{CO}_{2}$ emissions, and this scenario might be worsened by the population growth. As the global energy mix is still dominated by fossil fuel-based solutions and population growth might raise the energy demand, both these factors might add to the rise in $\mathrm{CO}_{2}$ emissions. This argument is validated by the model outcomes. This outcome falls in the similar lines with the finding of Sinha et al. (2020) for Next 11 economies. In summary, it can be concluded that the innovation-led economic growth trajectory across the world might provide a solution to the energy security and environmental degradation problems by promoting energy efficiency and renewable energy solutions. As the world has experienced a rise in technological innovations during the COVID-19 outbreak, it might be expected that these innovations my lead the nations toward achieving environmental sustainability during the post-COVID period.

Apart from the environmental impact, the innovation-led economic growth trajectory experiences a social impact. The estimation outcomes of this impact are reported in Table 10. The model outcomes reveal that the unemployment-TFP association resembles a $U$-shaped association, consistent across three estimation methods. This insight indicates a socially unsustainable economic growth trajectory, as unemployment rises after a decline and reaches a certain threshold. As the economic growth might raise the level of unemployment, it might affect the social balance due to the skewed income distribution. Depending on the extent of capital and technology intensiveness of the sectoral structure in the era of Industry 4.0, the level of unemployment might vary. This outcome falls in the similar lines with the theoretical findings of Boone (2000) and empirical finding of Beynon et al. (2019) for the USA. By observing the turnaround points of this association, it can be deduced that they are very close to the top percentile of the sample, despite their presence outside the sample range. It indicates that given the economic growth trajectory prevails, the world might experience a social imbalance during the post-COVID period, leading to a potential roadblock to achieve the objectives of SDG 8, i.e. decent work and economic growth. This situation can be aggravated in the countries with high population growth due to the excess supply of labor rather than the demand. The model outcomes substantiate this claim by revealing the positive impact of population on unemployment. Along with this situation, the technology 
transfer via globalization channel might replace labor by technology, thus raising unemployment. The positive impact of globalization on unemployment, as revealed by the estimation outcomes, validates this argument. This outcome corroborates the finding of Gozgor (2017). However, the model outcomes also divulge that the energy usage pattern might affect unemployment by boosting labor-intensive manufacturing activities. The outcome extends the findings of Mbarek et al. (2018) for Tunisia. To complement this argument, the impact of structural transformation of the economy might be crucial. Given the impact of the structural transformation to be negative on unemployment, and given the upper-middle- and high-income countries promoting technologies in place of manual laborers, it might be possible that the surplus labor force is potentially migrating toward the countries with comparatively lower income levels. Therefore, surplus labor of one country might be catering to the demand of labor in the other countries. However, this impact cannot be a sustainable one, given the high population growth in the destination countries.

As both the impacts of the innovation-led economic growth have been discussed, along with the impacts of other relevant policy instruments, it is necessary to facilitate a holistic depiction by analyzing both scenarios together. Graphical representation of both the associations is provided in Figure 1, where the $\mathrm{CO}_{2}$ emissions-TFP association is inverted $U$-shaped and the unemployment-TFP association is $U$-shaped. As the rise in TFP affects the $\mathrm{CO}_{2}$ emissions and unemployment in opposite ways, the policy trade-off situation becomes evident in Figure 1. As the best solution might not be achievable in such a scenario, an optimum policy mix between these two competing objectives needs to be devised. In Figure 2, a vivid depiction of this situation is presented. It is assumed that both $\mathrm{CO}_{2}$ emissions and unemployment are at equilibrium at point $\mathrm{PI}_{1}$. At this point, $\mathrm{CO}_{2}$ emissions and unemployment are denoted by $\mathrm{CE}_{1}$ and $\mathrm{UE}_{1}$, respectively. This equilibrium is achieved during the pre-COVID situation. Beyond this point, both $\mathrm{CO}_{2}$ emissions and unemployment start exhibiting a decline in their growth rates, and both these target policy parameters achieve their respective thresholds. It is worthwhile to mention that at any point in time, either of the two policy parameters can be considered due to the opposite evolutionary impacts of TFP on these parameters. At any particular value of TFP at time $t$ (between preand post-COVID periods), the value of $\mathrm{CO}_{2}$ emissions is presented as $\mathrm{CE}_{t}^{*}$, and the value of unemployment is denoted as $\mathrm{UE}_{t}^{*}$. Now, toward the left side of time $t, \mathrm{CO}_{2}$ emission is rising
Innovational duality and sustainable development

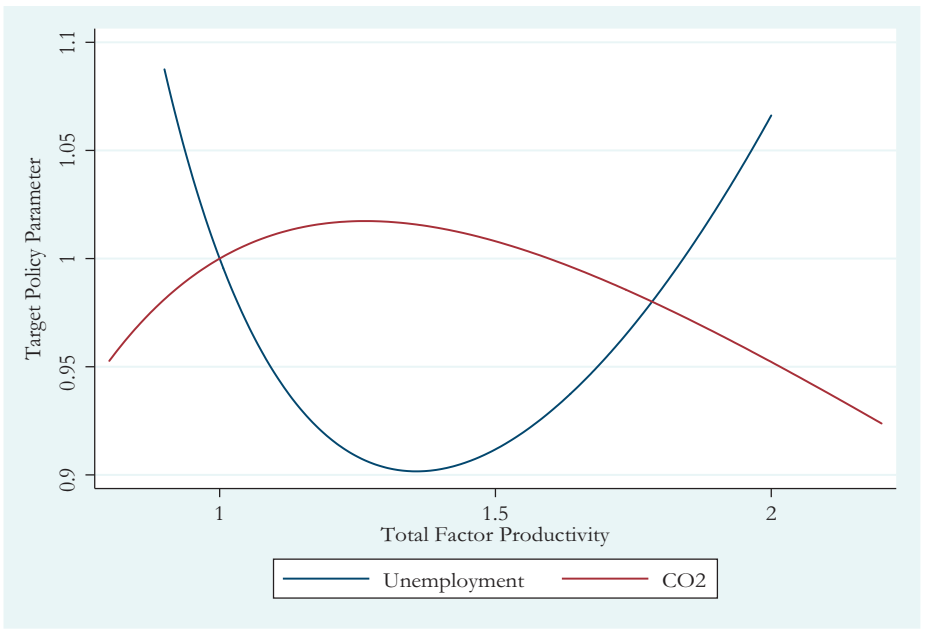

Figure 1.

Environmental and social impacts of TFP 
JEIM
35,1

\section{2}

Figure 2.

Diagrammatic representation of policy intervention points

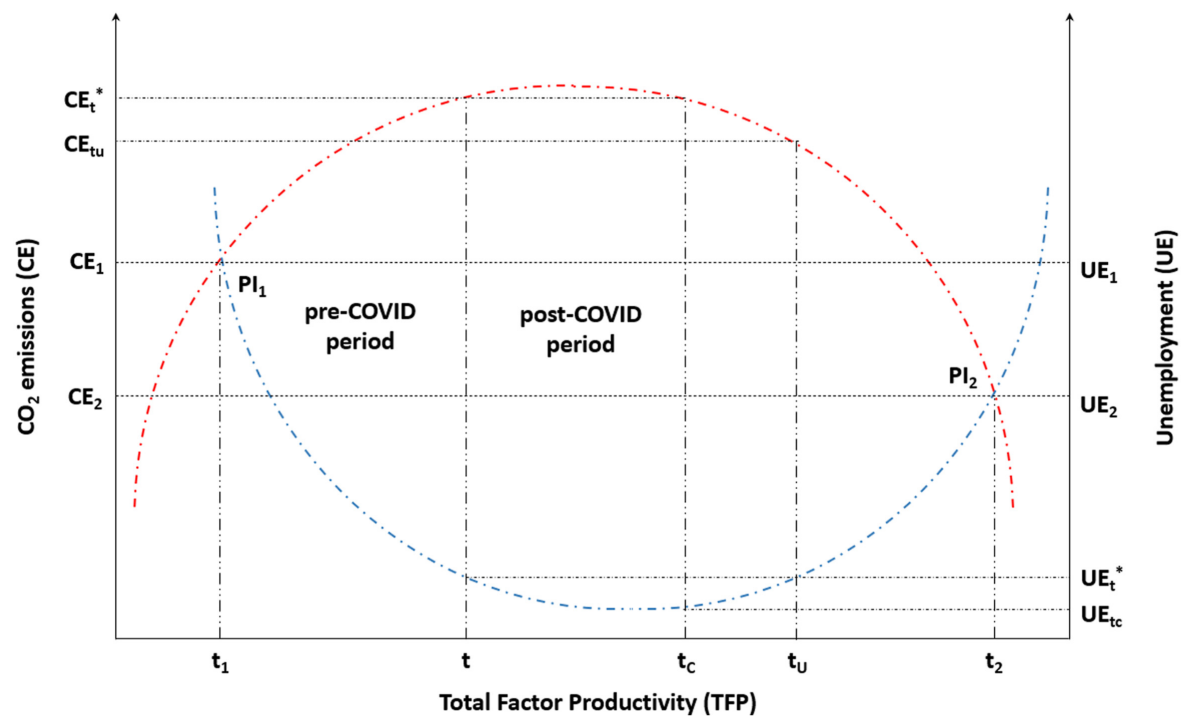

and unemployment is falling, while toward the right side of time $t, \mathrm{CO}_{2}$ emission is falling and unemployment is rising beyond the threshold limit. Also, it is observed that both $\mathrm{CE}_{t}^{*}$ and $\mathrm{UE}_{t}^{*}$ appear again at time $t_{c}$ and $t_{u}$, on the $\mathrm{CO}_{2}$ emissions-TFP and unemployment-TFP graphs, respectively. Now, if these two scenarios are compared with the ones at time $t$, then the following conditions can be derived:

Condition 1. When $\mathrm{CO}_{2}$ emissions are at $\mathrm{CE}_{t}^{*}$ :

(1) $\left.\frac{\partial \mathrm{UE}_{n}}{\partial \mathrm{TFP}_{n}}\right|_{n=t}<\left.\frac{\partial \mathrm{UE}_{n}}{\partial \mathrm{TFP}_{n}}\right|_{n=t_{c}}, n \in R, t<t_{c}$

(2) $\mathrm{UE}_{t}^{*}>\mathrm{UE}_{t c}, t<t_{c}$

Condition 2. When unemployment is at $\mathrm{UE}_{t}^{*}$ :

(1) $\left.\frac{\partial \mathrm{CE}_{n}}{\partial \mathrm{TFP}_{n}}\right|_{n=t}>\left.\frac{\partial \mathrm{CE}_{n}}{\partial \mathrm{TFP}_{n}}\right|_{n=t_{u}}, n \in R, t<t_{u}$

(2) $\mathrm{CE}_{t}^{*}>\mathrm{CE}_{t u}, t<t_{u}$

Hence, it can be observed that both before and after the occurrence of the turnaround points of the associations, any given value of TFP cannot simultaneously reduce the level of $\mathrm{CO}_{2}$ emissions and unemployment. Hence, the question of policy trade-off arises. Now, the parallel attainment of SDGs 13 and 8 might be crucial during the post-COVID scenario because of these opposite effects. As none of the associations can attain their optimal values, therefore, a policy optimum needs to be devised to achieve a policy-level solution. This optimum can be obtained at the intersection point of both these associations. In Figure 2, both these associations intersect each other at $\mathrm{PI}_{1}$ and $\mathrm{PI}_{2}$. It signifies that the policy optimum can combine both values and does not require individual optimal values. As innovation is an irreversible process, $\mathrm{PI}_{1}$ cannot be considered the policy optimum. Hence, from a futuristic perspective, the social and environmental impacts of TFP might meet again at $\mathrm{PI}_{2}$, expected to occur during the post-COVID period. Though this point represents neither of the individual optimum values, attainment of this point might be crucial from the perspective of policy- 
making. The policymakers might be interested in accelerating the achievement of both the turnaround points, followed by delaying the occurrence of $\mathrm{PI}_{2}$. For this reason, both the curves flatten toward the right.

\section{Conclusion and policy implications}

The dual impacts of innovation of $\mathrm{CO}_{2}$ emissions and unemployment are analyzed at a global scale, and the results indicate that innovation- $\mathrm{CO}_{2}$ emissions association follows an inverted $U$-shaped form, whereas the innovation-unemployment association follows a $U$-shaped form. The study outcomes divulge that a socio-ecological policy trade-off exists at the aggregate level as well as at various income levels. Based on the outcomes, a policy framework is recommended for addressing this policy trade-off.

\subsection{Implications for theory}

This study has made an attempt to extend the famous "Capital-labor substitution" principle proposed by Arrow et al. (1961). The seminal work by Arrow et al. (1961) shows that the economic efficiency in the international trade might be achieved by substituting capital with human labor. It gave an indication that the human laborers will be substituted by the capital following a shape convex to the origin. However, the notion of technological development during that study was limited to the manufacturing sector, which was characteristically labor-intensive. With the advent of technological innovations in the age of Industry 4.0 and growth of the service sector, the notion of technological development has undergone a transformation. Hence, the work of Arrow et al. (1961) might be extended from a convex curve, following the evolutionary nature of technological innovations. Moreover, the "Capitallabor substitution" principle majorly looked into the unidimensional aspect of capital. In the SDG regime, the innovation is expected to play a dual role - in environmental and social dimensions. Therefore, the "Capital-labor substitution" principle required an extension from the socio-ecological tradeoff perspective.

From theoretical point of view, this study has shown how technological innovations can initiate socio-ecological tradeoff. Given these competing objectives, innovation can be viewed as a policy instrument appearing as an environmental boon and a social curse. Ideally, innovation has been perceived as a tool for bringing environmental benefits. The studies by Anthony et al. (2018) and Xie et al. (2021) indicate the environmental benefits of innovation. However, the recent work by Chen et al. (2021) indicates the negative social externalities exerted by innovation. Moreover, the "New Approaches to Economic Challenges" by OECD (2020) talk about reinventing the role of innovation in addressing policy tradeoffs, which are inclined toward managing the social sustainability aspects. From this viewpoint, technological innovation is assumed to have a negative social impact. Now, when the nations are embarking on innovation to achieve the SDGs, the policy dimensions should take care of this aspect. This consideration gives the academic literature a direction about how to visualize innovational duality in policy-making.

In this view, the theoretical framework of EKC hypothesis needs to be mentioned. By far, the literature of energy and environmental economics visualized EKC hypothesis as a tool for measuring environmental impact assessment. However, the capability of EKC hypothesis to encapsulate the evolutionary impact of the policy instruments on the target policy parameter has been largely ignored (Balsalobre-Lorente et al., 2021). The quadratic specification of EKC hypothesis gives a leverage to analyze the nonlinear evolutionary impact over a temporal frame, and hence, this framework can be utilized as a policy forecasting tool. Going beyond the traditional environmental impact assessment, this study has shown the power of EKC
Innovational duality and sustainable development 
JEIM

35,1

hypothesis in analyzing the policy tradeoff. To bring additional insights to the analysis, the cubic specification of the EKC hypothesis can be utilized (Sinha et al., 2019). In that process, capturing the movement of the inflection point appearing between the two turnaround points can uncover further intuitions regarding the possible policy tradeoffs.

\subsection{Implications for policymakers}

As the innovation influences both $\mathrm{CO}_{2}$ emissions and unemployment, it is not possible to arrive at the best solution for either of the cases due to the opposite nature of the impacts. Therefore, this policy trade-off requires an optimum solution, which will bring the social and ecological impacts of innovation at a certain equilibrium. Hence, the objective of the policy framework should be focused at achieving this equilibrium during the post-COVID period. Now, this policy framework can be designed following a phase-wise schedule. As the impact of technological innovation will be immediately visible on the $\mathrm{CO}_{2}$ emissions, therefore the first phase of the policy framework should focus on the ecological impact of innovation. For the innovation to achieve its full potential in $\mathrm{CO}_{2}$ emissions reduction, the policymakers should adopt appropriate measures to reduce the reluctance of the industrial sector to accept these solutions. Moreover, as continued dependence on the fossil fuel solutions might reduce the potential impact of innovation on the $\mathrm{CO}_{2}$ emissions, a gradual shift from the nonrenewable to renewable energy sources is also required. A drastic fall in the anthropogenic activities during the COVID-19 outbreak has highlighted the emergence of service sector firms. Now the policymakers might need to bring certain policy interventions for their respective nations towards being recognized as service-oriented economies for retaining the environmental quality. Now, in such a situation, overnight sectoral overhaul might create deterrence to the prevailing economic growth pattern of these countries. Therefore, policymakers might need to use the existing financialization channels in such a way so that the firms can embrace the innovations in a hassle-free manner within a predefined time. For this purpose, the financial institutions can introduce the concept of discriminatory interest rates on loans and advances for availing the innovative solutions, whereas this discrimination might be based on the carbon footprint of the firms. Hence, given a fixed period, the dirtier firms will be compelled to avail the solutions at a higher rate of interest, whereas the cleaner firms will enjoy a lower rate of interest. Thus, the economic system in the countries will encourage the adoption of cleaner energy solutions and innovation. During this finance-driven transition, it should be remembered that the higher bracket of the interest rate should not be higher than the existing average cost of capital of the firms. Otherwise, it might dissuade the firms to embrace the innovation for improving the quality of their production systems. Additionally, they might stop the business operations. Hence, the rate of interest should not be a deterrence in the innovation adoption process.

Once this phase becomes operational, the second phase of the framework should be designed to internalize the negative social externalities. As the rising diffusion of innovation is starting to replace the human labors after the deployment and implementation period, there is a requirement of an early policy intervention. When the firms start implementing the innovative solutions in their existing production processes, there should be an upper threshold of innovation for the firms, beyond which they will not be able to replace human labour with technology. Following equations (3) and (4), the level of TFP can be denoted as per the following [1]:

$$
\mathrm{TFP}^{*}=\max \left[\left\{-\left(\alpha_{1}-\gamma_{1}\right) \pm \sqrt{\left(\alpha_{1}-\gamma_{1}\right)^{2}-4\left(\alpha_{0}-\gamma_{0}\right)\left(\alpha_{2}-\gamma_{2}\right)}\right\} / 2\left(\alpha_{2}-\gamma_{2}\right)\right]
$$

Here, $\alpha_{0}, \alpha_{1}, \alpha_{2}, \gamma_{0}, \gamma_{1}, \gamma_{2} \neq 0$ and $\left(\alpha_{1}-\gamma_{1}\right)^{2} \geq 4\left(\alpha_{0}-\gamma_{0}\right)\left(\alpha_{2}-\gamma_{2}\right)$ 
At the point denoted in equation (11), the level of TFP to be achieved by any firm allows it to tread along the long-run equilibrium growth trajectory. Moving beyond this point might help the firm to gain a short-run economic profit at the cost of employment. Now, the rise in consequential unemployment might create a demand pressure in the economy, leading to the reduction in supply and production. Treading along the long-run equilibrium growth path necessitates the production to continue. For this purpose, certain short-run economic losses need to be incurred. Therefore, the policymakers need to ensure that the policy intervention point should be achieved immediately after the first phase of the policy framework is implemented to keep the economic growth trajectory intact. The accomplishment of the first phase of the policy framework will help these countries in achieving the objectives of SDG 13, whereas the second phase will allow these nations to achieve the objectives of SDG 8. Thus, this policy framework ensures sustainable development in the post-COVID scenario.

While the core policy framework helps these nations to avoid the policy trade-off, the tangential policy framework helps to sustain the core policy framework. After the first two phases of the policy framework being operational, policymakers need to gradually control the population growth rate. If the population growth rate is higher than the growth rate of job opportunities, it creates the unemployment issue. As a result, the core policy framework might not be able to achieve its full potential. Hence, strict population control mechanisms should be devised by policymakers. Moreover, the policymakers should encourage the start-up ventures with these technologies to diffuse the innovations in a more effective manner. However, the capital allocation should be done in such a way so that the firm can generate enough employment, not fully replacing the labor with technology. For institutionalizing these solutions, the educational curriculum should be amended. It can raise the students' awareness of the latest technological developments and innovations across the nations and the social and ecological benefits of innovation. Thus, it will help the nations in accomplishing the objectives of SDG 9 (industry, innovation and infrastructure) and SDG 4 (quality education).

\subsection{Policy caveats and assumptions}

Discussion of a policy framework is seemingly incomplete without mentioning the caveats and assumptions behind the framework. Understanding these two aspects is necessary, as their non-fulfillment might hinder the policy framework from reaching its full potential (Cheng et al., 2021a, b). First, during bringing discrimination in the interest rate, the slabs should be made close so that many firms can be encapsulated. Second, policymakers need to introduce rehabilitation policies and vocation centers for the labor employed in the traditional fossil fuel-based energy generation sector. Third, the rent-seeking mechanism in the bureaucratic system should be brought to the minimum, as such incidents of corruption hinder the diffusion of innovation within and across the borders.

\subsection{Limitations and future projections}

Though this study has introduced a critical policy dimension by describing the socioecological policy trade-off initiated by innovation, the study might suffer from certain limitations. One of the major limitations of the study is that only the output indicator of innovation is considered, while various other forms of innovation (e.g. social innovation, environmental innovation) have not been incorporated. Though theoretically proven, putting forth a generalized view of innovation might yield different results in the empirical pursuit. Saying about this limitation, this is also needed to clarify that the policy framework introduced in this study can serve as a baseline policy approach for addressing the policy trade-off in any context. Moreover, the framework is flexible to accommodate any additional policy instrument, which might be contextually suitable. This flexibility and generalizability have made this policy framework a contribution to the literature. Future studies in this direction can be carried out by considering various forms of innovation and how those forms can demonstrate socio-ecological trade-offs in various contexts.
Innovational duality and sustainable development 
JEIM 35,1

\section{Note}

1. In this calculation, the matrix of other variables is disregarded, as the FOC eventually nullifies them.

\section{References}

Al-Dalaeen, Q.R., Sivarajah, U. and Irani, Z. (2021), "Determining sustainability key performance indicators for food loss reduction", Journal of Enterprise Information Management, Vol. 34, pp. 733-745.

Amri, F., Zaied, Y.B. and Lahouel, B.B. (2019), "ICT, total factor productivity, and carbon dioxide emissions in Tunisia”, Technological Forecasting and Social Change, Vol. 146, pp. 212-217.

Anthony, B., Jr, Majid, M.A. and Romli, A. (2018), "A collaborative agent based green IS practice assessment tool for environmental sustainability attainment in enterprise data centers", Journal of Enterprise Information Management, Vol. 31, pp. 771-795.

Antweiler, W., Copeland, B.R. and Taylor, M.S. (2001), "Is free trade good for the environment?", American Economic Review, Vol. 91, pp. 877-908.

Arrow, K.J., Chenery, H.B., Minhas, B.S. and Solow, R.M. (1961), "Capital-labor substitution and economic efficiency", The Review of Economics and Statistics, Vol. 43, pp. 225-250.

Bag, S., Pretorius, J.H.C., Gupta, S. and Dwivedi, Y.K. (2021), "Role of institutional pressures and resources in the adoption of big data analytics powered artificial intelligence, sustainable manufacturing practices and circular economy capabilities", Technological Forecasting and Social Change, Vol. 163, 120420.

Balsalobre-Lorente, D., Sinha, A., Driha, O.M. and Mubarik, M.S. (2021), "Assessing the impacts of ageing and natural resource extraction on carbon emissions: a proposed policy framework for European economies", Journal of Cleaner Production, Vol. 296, 126470.

Benavente, J.M. and Lauterbach, R. (2008), "Technological innovation and employment: complements or substitutes?", The European Journal of Development Research, Vol. 20, pp. 318-329.

Beynon, M.J., Jones, P. and Pickernell, D. (2019), "The role of entrepreneurship, innovation, and urbanity-diversity on growth, unemployment, and income: US state-level evidence and an fsQCA elucidation”, Journal of Business Research, Vol. 101, pp. 675-687.

Boone, J. (2000), "Technological progress, downsizing and unemployment", The Economic Journal, Vol. 110, pp. 581-600.

Chen, M., Sinha, A., Hu, K. and Shah, M.I. (2021), "Impact of technological innovation on energy efficiency in Industry 4.0 era: moderation of shadow economy in sustainable development", Technological Forecasting and Social Change, Vol. 164, 120521.

Cheng, Y., Awan, U., Ahmad, S. and Tan, Z. (2021a), "How do technological innovation and fiscal decentralization affect the environment? A story of the fourth industrial revolution and sustainable growth”, Technological Forecasting and Social Change, Vol. 162, 120398.

Cheng, Y., Sinha, A., Ghosh, V., Sengupta, T. and Luo, H. (2021b), "Carbon tax and energy innovation at crossroads of carbon neutrality: designing a sustainable decarbonization policy", Journal of Environmental Management, Vol. 294, 112957.

Chien, F., Anwar, A., Hsu, C.C., Sharif, A., Razzaq, A. and Sinha, A. (2021), "The role of information and communication technology in encountering environmental degradation: proposing an SDG framework for the BRICS countries”, Technology in Society, Vol. 65, 101587.

Chudik, A. and Pesaran, M.H. (2015), "Common correlated effects estimation of heterogeneous dynamic panel data models with weakly exogenous regressors", Journal of Econometrics, Vol. 188, pp. 393-420.

du Can, S.D.I.R. and Price, L. (2008), "Sectoral trends in global energy use and greenhouse gas emissions”, Energy Policy, Vol. 36, pp. 1386-1403. 
Evangelista, R. and Savona, M. (2002), "The impact of innovation on employment in services: evidence from Italy", International Review of Applied Economics, Vol. 16, pp. 309-318.

Evangelista, R. and Vezzani, A. (2012), "The impact of technological and organizational innovations on employment in European firms", Industrial and Corporate Change, Vol. 21 No. 4, pp. 871-899.

Gagliardi, L. (2019), "The impact of foreign technological innovation on domestic employment via the industry mix", Research Policy, Vol. 48, pp. 1523-1533.

Gashenko, I.V., Khakhonova, N.N., Orobinskaya, I.V. and Zima, Y.S. (2020), "Competition between human and artificial intellectual capital in production and distribution in Industry 4.0", Journal of Intellectual Capital, Vol. 21, pp. 531-547.

Gozgor, G. (2017), "The impact of globalization on the structural unemployment: an empirical reappraisal", International Economic Journal, Vol. 31, pp. 471-489.

Greenan, N. and Guellec, D. (2000), "Technological innovation and employment reallocation”, Labour, Vol. 14, pp. 547-590.

Grossman, G.M. and Kruger, A.G. (1991), "Environmental influences of a North American free trade agreement", Working paper 3914, National Bureau of Economic Research.

Grover, P., Kar, A.K., Gupta, S. and Modgil, S. (2021), "Influence of political leaders on sustainable development goals-insights from Twitter", Journal of Enterprise Information Management. doi: 10.1108/JEIM-07-2020-0304.

Gupta, S., Bag, S., Jabbour, C.C. and Sarkis, J. (2021), "SI: call for papers: reimagining post-pandemic enterprise information management and achieving sustainable development goals", Journal of Enterprise Information Management, available at: https://www.emeraldgrouppublishing.com/ journal/jeim/reimagining-post-pandemic-enterprise-information-management-and-achievingsustainable (accessed 3 September 2021).

Gurbuz, I.B. and Ozkan, G. (2020), "Transform or perish: preparing the business for a post-pandemic future", IEEE Engineering Management Review, Vol. 48 No. 3, pp. 139-145, doi: 10.1109/EMR. 2020.3014693.

Gygli, S., Haelg, F., Potrafke, N. and Sturm, J.E. (2019), "The KOF globalization index-revisited”, The Review of International Organizations, Vol. 14, pp. 543-574.

Hörisch, J. (2021), "The relation of COVID-19 to the UN sustainable development goals: implications for sustainability accounting, management and policy research", Sustainability Accounting, Management and Policy Journal, Vol. 12 No. 5, pp. 877-888, doi: 10.1108/SAMPJ-08-2020-0277.

Jha, A.K. and Bose, I. (2015), "Innovation styles, processes, and their drivers: an organizational perspective technology, innovation, and enterprise transformation", Technology, Innovation, and Enterprise Transformation, pp. 143-163, doi: 10.4018/978-1-4666-6473-9.ch007.

Koh, L., Orzes, G. and Jia, F. (2019), "The fourth industrial revolution (Industry 4.0): technologies disruption on operations and supply chain management", International Journal of Operations and Production Management, Vol. 39 Nos 6/7/8, pp. 817-828, doi: 10.1108/IJOPM-08-2019-788.

Kovacs, O. (2018), "The dark corners of Industry 4.0-grounding economic governance 2.0", Technology in Society, Vol. 55, pp. 140-145.

Levinson, A. and Taylor, M.S. (2008), "Unmasking the pollution haven effect”, International Economic Review, Vol. 49, pp. 223-254.

Lilien, D.M. (1982), "Sectoral shifts and cyclical unemployment”, Journal of Political Economy, Vol. 90, pp. 777-793.

Marić, J., Galera-Zarco, C. and Opazo-Basáez, M. (2021), "The emergent role of digital technologies in the context of humanitarian supply chains: a systematic literature review", Annals of Operations Research, pp. 1-42, doi: 10.1007/s10479-021-04079-z.

Mbarek, M.B., Abdelkafi, I. and Feki, R. (2018), "Nonlinear causality between renewable energy, economic growth, and unemployment: evidence from Tunisia", Journal of the Knowledge Economy, Vol. 9, pp. 694-702.
Innovational duality and sustainable development 
JEIM

35,1

318

Mensah, C.N., Long, X., Boamah, K.B., Bediako, I.A., Dauda, L. and Salman, M. (2018), "The effect of innovation on CO 2 emissions of OCED countries from 1990 to 2014", Environmental Science and Pollution Research, Vol. 25, pp. 29678-29698.

Modgil, S., Gupta, S. and Bhushan, B. (2020), "Building a living economy through modern information decision support systems and UN sustainable development goals", Production Planning and Control, Vol. 31, pp. 967-987.

Modgil, S., Singh, R.K. and Hannibal, C. (2021), "Artificial intelligence for supply chain resilience: learning from COVID-19", The International Journal of Logistics Management. doi: 10.1108/ IJLM-02-2021-0094.

Mukarram, M. (2020), "Impact of COVID-19 on the UN sustainable development goals (SDGs)", Strategic Analysis, Vol. 44, pp. 253-258.

Organisation for Economic Co-Operation and Development (OECD) (2020), New Approaches to Economic Challenges (NAEC), available at: https://www.oecd.org/naec/New_Decade_New_ Approaches.pdf (accessed 1 August 2021).

Opazo-Basáez, M., Vendrell-Herrero, F., Bustinza, O.F. and Marić, J. (2021), "Global value chain breadth and firm productivity: the enhancing effect of Industry 4.0", Journal of Manufacturing Technology Management, Vol. ahead-of-print No. ahead-of-print, doi: 10.1108/JMTM-12-2020-0498.

Ortt, R., Stolwijk, C. and Punter, M. (2020), "Implementing Industry 4.0: assessing the current state", Journal of Manufacturing Technology Management, Vol. ahead-of-print No. ahead-ofprint, doi: 10.1108/JMTM-07-2020-0284.

Pan, S.L. and Zhang, S. (2020), "From fighting COVID-19 pandemic to tackling sustainable development goals: an opportunity for responsible information systems research", International Journal of Information Management, Vol. 55, 102196.

Pesaran, M.H. (2006), "Estimation and inference in large heterogeneous panels with a multifactor error structure”, Econometrica, Vol. 74, pp. 967-1012.

Pesaran, M.H. (2007), "A simple panel unit root test in the presence of cross-section dependence", Journal of Applied Econometrics, Vol. 22, pp. 265-312.

Phillips, P.C. and Sul, D. (2003), "Dynamic panel estimation and homogeneity testing under cross section dependence", The Econometrics Journal, Vol. 6, pp. 217-259.

Serajuddin, U. and Hamadeh, N. (2020), New World Bank Country Classifications by Income Level: 2020-2021, World Bank, available at: https://blogs.worldbank.org/opendata/new-world-bankcountry-classifications-income-level-2020-2021 (accessed 12 June 2021).

Shahbaz, M. and Sinha, A. (2019), "Environmental Kuznets curve for CO2 emissions: a literature survey", Journal of Economic Studies, Vol. 46, pp. 106-168.

Sharif, A., Godil, D.I., Xu, B., Sinha, A., Khan, S.A.R. and Jermsittiparsert, K. (2020), "Revisiting the role of tourism and globalization in environmental degradation in China: fresh insights from the quantile ARDL approach", Journal of Cleaner Production, Vol. 272, 122906.

Sinha, A., Sengupta, T. and Alvarado, R. (2020), "Interplay between technological innovation and environmental quality: formulating the SDG policies for next 11 economies", Journal of Cleaner Production, Vol. 242, 118549.

Sinha, A., Shahbaz, M. and Balsalobre, D. (2019), "Data selection and environmental Kuznets curve models-environmental Kuznets curve models, data choice, data sources, missing data, balanced and unbalanced panels", in Environmental Kuznets Curve (EKC), Academic Press, pp. 65-83.

Thornton, J. (2020), "COVID-19 pandemic has derailed progress on sustainable development goals, says WHO”, BMJ: British Medical Journal, Vol. 369, pp. 1-1, doi: 10.1136/bmj.m1969.

Unalan, S. and Ozcan, S. (2020), "Democratising systems of innovations based on blockchain platform technologies", Journal of Enterprise Information Management, Vol. 33, pp. 1511-1536.

Van der Waal, J.W., Thijssens, T. and Maas, K. (2021), "The innovative contribution of multinational enterprises to the sustainable development goals", Journal of Cleaner Production, Vol. 285, 125319. 
Vivarelli, M. (2015), Innovation and Employment, World of Labor, Institute of Labor Economics (IZA), Bonn.

Wang, Z., Huang, W. and Chen, Z. (2019), "The peak of $\mathrm{CO}_{2}$ emissions in China: a new approach using survival models", Energy Economics, Vol. 81, pp. 1099-1108.

Westerlund, J. (2007), "Testing for error correction in panel data", Oxford Bulletin of Economics and Statistics, Vol. 69, pp. 709-748.

World Bank (2021), World Development Indicators, available at: https://data.worldbank.org/indicator (accessed 15 June 2021).

Xie, Z., Qu, L., Lin, R. and Guo, Q. (2021), "Relationships between fluctuations of environmental regulation, technological innovation, and economic growth: a multinational perspective", Journal of Enterprise Information Management. doi: 10.1108/JEIM-02-2021-0104.

$\mathrm{Xu}$, L.D., Xu, E.L. and Li, L. (2018), "Industry 4.0: state of the art and future trends", International Journal of Production Research, Vol. 56 No. 8, pp. 2941-2962.

Zhu, C., Qiu, Z. and Liu, F. (2021), "Does innovation stimulate employment? Evidence from China", Economic Modelling, Vol. 94, pp. 1007-1017.

\section{Appendix}

\begin{tabular}{|c|c|c|c|c|c|c|c|c|}
\hline Country & $\begin{array}{l}\text { Income } \\
\text { category }\end{array}$ & Country & $\begin{array}{l}\text { Income } \\
\text { category }\end{array}$ & Country & $\begin{array}{l}\text { Income } \\
\text { category }\end{array}$ & Country & $\begin{array}{l}\text { Income } \\
\text { category }\end{array}$ & \\
\hline Angola & LMI & $\begin{array}{l}\text { Egypt, } \\
\text { Arab Rep. }\end{array}$ & LMI & Latvia & $\mathrm{HI}$ & Romania & $\mathrm{HI}$ & \\
\hline Argentina & UMI & Estonia & $\mathrm{HI}$ & Lithuania & $\mathrm{HI}$ & $\begin{array}{l}\text { Russian } \\
\text { Federation }\end{array}$ & UMI & \\
\hline Armenia & UMI & Finland & $\mathrm{HI}$ & Luxembourg & $\mathrm{HI}$ & $\begin{array}{l}\text { Saudi } \\
\text { Arabia }\end{array}$ & $\mathrm{HI}$ & \\
\hline Australia & $\mathrm{HI}$ & France & $\mathrm{HI}$ & Malaysia & UMI & Senegal & LMI & \\
\hline Austria & $\mathrm{HI}$ & Gabon & UMI & Mauritius & $\mathrm{HI}$ & Singapore & $\mathrm{HI}$ & \\
\hline Belgium & $\mathrm{HI}$ & Germany & $\mathrm{HI}$ & Mexico & UMI & $\begin{array}{l}\text { South } \\
\text { Africa }\end{array}$ & UMI & \\
\hline Benin & LMI & Greece & $\mathrm{HI}$ & Mongolia & LMI & Spain & $\mathrm{HI}$ & \\
\hline Bolivia & LMI & Guatemala & UMI & Morocco & LMI & Sri Lanka & LMI & \\
\hline Botswana & UMI & Honduras & LMI & Mozambique & LI & Sudan & LI & \\
\hline Brazil & UMI & Hungary & HI & Namibia & UMI & Sweden & $\mathrm{HI}$ & \\
\hline Bulgaria & UMI & Iceland & $\mathrm{HI}$ & $\begin{array}{l}\text { The } \\
\text { Netherlands }\end{array}$ & $\mathrm{HI}$ & Switzerland & $\mathrm{HI}$ & \\
\hline Cameroon & LMI & India & LMI & New Zealand & $\mathrm{HI}$ & Tajikistan & LI & \\
\hline Canada & $\mathrm{HI}$ & Indonesia & UMI & Nicaragua & LMI & Thailand & UMI & \\
\hline Chile & $\mathrm{HI}$ & $\begin{array}{l}\text { Iran, Islamic } \\
\text { Rep. }\end{array}$ & UMI & Niger & LI & Togo & LI & \\
\hline China & UMI & Iraq & UMI & Nigeria & LMI & $\begin{array}{l}\text { Trinidad } \\
\text { and Tobago }\end{array}$ & $\mathrm{HI}$ & \\
\hline $\begin{array}{l}\text { Hong Kong } \\
\text { SAR, China }\end{array}$ & $\mathrm{HI}$ & Ireland & $\mathrm{HI}$ & Norway & $\mathrm{HI}$ & Tunisia & LMI & \\
\hline Colombia & UMI & Israel & $\mathrm{HI}$ & Panama & $\mathrm{HI}$ & Turkey & UMI & \\
\hline Costa Rica & UMI & Italy & HI & Paraguay & UMI & Tanzania & LMI & \\
\hline $\begin{array}{l}\text { Côte } \\
\text { d'Ivoire }\end{array}$ & LMI & Jamaica & UMI & Peru & UMI & Ukraine & LMI & \\
\hline Croatia & $\mathrm{HI}$ & Japan & HI & Philippines & LMI & UK & $\mathrm{HI}$ & \\
\hline Cyprus & $\mathrm{HI}$ & Jordan & UMI & Poland & $\mathrm{HI}$ & USA & $\begin{array}{l}\mathrm{HI} \\
\text { continued) }\end{array}$ & $\begin{array}{r}\text { Table A1. } \\
\text { List of sample } \\
\text { countries }\end{array}$ \\
\hline
\end{tabular}

Innovational duality and sustainable development 


\begin{tabular}{|c|c|c|c|c|c|c|c|c|}
\hline $\begin{array}{l}\text { JEIIVI } \\
35,1\end{array}$ & Country & $\begin{array}{l}\text { Income } \\
\text { category }\end{array}$ & Country & $\begin{array}{l}\text { Income } \\
\text { category }\end{array}$ & Country & $\begin{array}{l}\text { Income } \\
\text { category }\end{array}$ & Country & $\begin{array}{l}\text { Income } \\
\text { category }\end{array}$ \\
\hline & $\begin{array}{l}\text { Czech } \\
\text { Republic }\end{array}$ & $\mathrm{HI}$ & Kazakhstan & UMI & Portugal & $\mathrm{HI}$ & Uruguay & $\mathrm{HI}$ \\
\hline & Denmark & $\mathrm{HI}$ & Kenya & LMI & Qatar & $\mathrm{HI}$ & $\begin{array}{l}\text { Venezuela, } \\
\text { RB }\end{array}$ & UMI \\
\hline \multirow[t]{2}{*}{320} & \multirow{2}{*}{$\begin{array}{l}\text { Dominican } \\
\text { Republic } \\
\text { Ecuador }\end{array}$} & \multirow{2}{*}{$\begin{array}{l}\text { UMI } \\
\text { UMI }\end{array}$} & \multirow{2}{*}{$\begin{array}{l}\text { Kyrgyz } \\
\text { Republic } \\
\text { Lao PDR }\end{array}$} & \multirow{2}{*}{$\begin{array}{l}\text { LMI } \\
\text { LMI }\end{array}$} & \multirow{2}{*}{$\begin{array}{l}\text { Korea, Rep. } \\
\text { Moldova }\end{array}$} & \multirow{2}{*}{$\begin{array}{l}\text { HI } \\
\text { LMI }\end{array}$} & \multirow{2}{*}{$\begin{array}{l}\text { Zambia } \\
\text { Zimbabwe }\end{array}$} & \multirow{2}{*}{$\begin{array}{l}\text { LMI } \\
\text { LMI }\end{array}$} \\
\hline & & & & & & & & \\
\hline Table A1. & Note(s): LI & ow income & LMI: Lower-m & ddle incom & UMI: Upper-1 & ddle incom & HI: High inco & \\
\hline
\end{tabular}

\begin{abstract}
About the authors
Dr Avik Sinha is an Associate Professor with Center for Excellence in Sustainable Development at Goa Institute of Management. He is a Fellow in Economics from Indian Institute of Management Indore. He has published several papers in Energy Policy, Energy, Technological Forecasting and Social Change, Journal of Environmental Management, Journal of Cleaner Production, Current Issues in Tourism, Renewable and Sustainable Energy Reviews, Ecological Indicators, etc. His current research interests include energy and environmental economics, applied econometrics, and sustainable development. He is presently working toward discovering the "Dark Sides of Innovation."

Arnab Adhikari is an Assistant Professor in the Operations Management area at the Indian Institute of Management Ranchi (IIM Ranchi). He has completed his PhD in Operations Management from the Indian institute of Management Calcutta. His research articles have appeared in the several reputed international journals and research handbooks such as European Journal of Operational Research, Transportation Research Part E; Logistics and Transportation Review, Annals of Operations Research, Informs Transactions on Education, INFOR: Information Systems and Operational Research, etc. His research interest includes economic modeling in operations management, sustainability, etc.

Ashish Kumar Jha is an Associate Professor in the field of Business Analytics at Trinity Business School, Trinity College Dublin. His research revolves around the areas of technology innovation and social media analysis. Ashish uses statistical and analytical techniques to understand how firms and consumers interact on social platforms and its effects for both firms and their consumers. His papers have been published in many top journals of the field JMIS, DSS, I\&M, IJPE, CAIS, among others. He has also presented his work at numerous top conferences of field, including ICIS, ECIS among others. Ashish Kumar Jha is the corresponding author and can be contacted at: akjha@tcd.ie
\end{abstract}

For instructions on how to order reprints of this article, please visit our website:

www.emeraldgrouppublishing.com/licensing/reprints.htm

Or contact us for further details: permissions@emeraldinsight.com 